\title{
Pengembangan E-Modul Matematika Berbasis PBL (Problem Based Learning) pada Materi Penyajian Data untuk Siswa SMP
}

\author{
Fatma Ramadanti ${ }^{1}$, Anwar Mutaqin ${ }^{2}$, Aan Hendrayana ${ }^{3}$ \\ ${ }^{1,2}$ Program Studi Pendidikan Matematika, Fakultas Keguruan dan Ilmu Pendidikan, Universitas Sultan Ageng Tirtayasa, \\ J1. Ciwaru Raya, Cipare, Kec. Serang, Kota Serang, Banten 42117 \\ fatmaramadanti18@gmail.com
}

\begin{abstract}
The objectives of this study are (1) to develop an e-module based on Problem Based Learning (PBL) mathematics on data presentation materials for junior high school students; (2) to find out the problem-based learning (PBL)based mathematics e-module on data presentation material for junior high school students; (3) to find out the practicality of Problem Based Learning (PBL)-based mathematics e-modules on the material presented to junior high school students; (4) to determine the effectiveness of Problem Based Learning (PBL)-based mathematics emodules on data presentation materials for junior high school students. This type of research is development research. The development model used in this study is the ADDIE (Analysis, Design, Development, Implementation, Evaluation) model. The quality of the developed math e-module can be seen from the validation sheet filled out by six validators, namely three material validators and three media validators. while the mathematics teacher response questionnaire and student response questionnaire were used to determine the practicality of the e-module and the completeness test used to determine the effectiveness of the developed emodule. The results of the development of Problem Based Learning (PBL)-based mathematics e-modules on data presentation materials for junior high school students got a "very valid" score from six validators, got a "very good" score from the mathematics teacher's response and student responses to the practicality of the e-module, and to test completeness individually 16 students out of 20 students classically completed $85 \%$ of students who completed so that it can be said that the developed mathematics e-module is effective for use in learning.
\end{abstract}

Keywords: E-module, PBL (Problem Based Learning), Data Presentation

\begin{abstract}
Abstrak
Tujuan dalam penelitian ini adalah (1) untuk mengembangkan e-modul matematika berbasis Problem Based Learning (PBL) pada materi penyajian data untuk siswa SMP; (2) untuk mengetahui kelayakan e-modul matematika berbasis Problem Based Learning (PBL) pada materi penyajian data untuk siswa SMP; (3) untuk mengetahui kepraktisan e-modul matematika berbasis Problem Based Learning (PBL) pada materi penyajian data untuk siswa SMP; (4) untuk mengetahui keefektifan e-modul matematika berbasis Problem Based Learning (PBL) pada materi penyajian data untuk siswa SMP. Jenis penelitian ini adalah penelitian pengembangan. Model pengembangan yang digunakan dalam penelitian ini adalah model ADDIE (Analysis, Design, Development, Implementation, Evaluation). E-modul matematika yang dikembangkan dapat diketahui kualitas kelayakannya dari lembar validasi yang diisi oleh enam validator yaitu tiga validator materi dan tiga validator media. sedangkan angket respon guru matematika dan angket respon siswa digunakan untuk mengetahui kepraktisan e-modul dan tes ketuntasan digunakan untuk mengetahui keefektifan dari e-modul yang dikembangkan. Hasil pengembangan e-modul matematika berbasis Problem Based Learning (PBL) pada materi penyajian data untuk siswa SMP mendapatkan penilaian "sangat valid" dari enam validator, mendapatkan nilai "sangat baik" dari respon guru matematika dan respon siswa untuk kepraktisan e-modul, dan untuk tes ketuntasan secara individual 16 siswa dari 20 siswa tuntas sedangkan secara klasikal 85\% siswa yang tuntas sehingga dapat disimpulkan bahwa e-modul matematika yang dikembangkan efektif untuk digunakan dalam pembelajaran.
\end{abstract}

Kata kunci: E-modul, PBL (Problem Based Learning), Penyajian Data

Copyright (c) 2021 Fatma Ramadanti, Anwar Mutaqin, Aan Hendrayana

$\triangle$ Corresponding author: Fatma Ramadanti

Email Address: fatmaramadanti18@gmail.com (Link. Mekar Jadi, Cilegon, Banten)

Received 28 June 2021, Accepted 30 June 2021, Published 21 August 2021

\section{PENDAHULUAN}

Matematika merupakan salah satu kebutuhan bagi kita semua, karena matematika berkaitan dengan kehidupan sehari-hari (Sirait, 2016). Selain itu, pembelajaran matematika memiliki tujuan untuk 
membekali siswa dalam kemampuan memecahkan masalah, berpikir kritis, logis, bernalar, abstrak, sistematis dan kreatif. Oleh karena itu, mempelajari matematika penting untuk siswa sebagai sumber daya yang berkualitas dan bermutu.

Sejak pandemi Covid-19, Menteri Pendidikan dan Kebudayaan mengeluarkan Surat Edaran Nomor 3 Tahun 2020 sebagai pencegahan corona virus (Covid-19) pada satuan pendidikan bahwa pembelajaran dilakukan di rumah secara online. Pandemi mempengaruhi pembelajaran matematika karena menghilangkan ruh matematika seperti memecahkan masalah, berpikir kritis, logis, bernalar, abstrak, sistematis dan kreatif (Sukadiono, radius setyawan, 2020). Dampak dari pembelajaran online membuat pembelajaran kurang maksimal. Pembelajaran online harus tetap berpegangan pada prinsip capaian pembelajaran dan memperhatikan akses siswa. Pendidik diharapkan untuk memahami terlebih dahulu kecenderungan belajar dengan memanfaatkan cara atau media belajar yang tepat agar siswa tertarik dalam mengikuti pembelajaran (Zhafira et al., 2020).

Salah satu materi dalam pelajaran matematika kelas VII semester II adalah penyajian data. Berdasarkan kurikulum, materi statistika terdapat dalam setiap jenjang pendidikan. Statistika adalah pengetahuan yang berhubungan cara pengumpulan, penyajian, pengolahan analisis data serta teknik analisis data (Zulfikri, 2016). Statistika digunakan untuk mengumpulkan, menyusun, meringakas, dan menyajikan data sehingga di perlukan untuk memahami dan membuat keputusan. Dalam mempelajari statistika, siswa di tuntut untuk mampu menyajikan sebuah data dengan tujuan memudahkan dalam membaca, memahami dan menganalisis data.

Pada siswa SMP kelas VII siswa diajarkan teknik penyajian data seperti tabel, diagram garis, diagram batang, dan diagram lingkaran. Sejalan dengan penelitian yang dilakukan oleh (Maryati \& Nanang, 2017) bahwa peserta didik mengalami beberapa kesulitan, diantaranya: kesulitan menganalisis dan klasifikasi jenis data dan menampilkan pada diagram atau tabel. Penyajian data berkaitan dengan kehidupan nyata sehingga dibutuhkan bahan ajar yang berkaitan dengan kehidupan sehari-hari. Materi penyajian data berkaitan erat dengan lingkungan sehari-hari sehingga memungkinkan untuk memunculkan masalah. Oleh karena itu, materi penyajian data cocok diajarkan dengan berorientasi pembelajaran berbasis masalah atau PBL (Problem Based Learning). Pendekatan PBL diharapkan dapat mengembangkan penalaran, komunikasi dankoneksi siswa dalam memecahkan masalah sehingga potensi intelektual siswa meningkat.

Model PBL (Problem Based Learning) cocok digunakan untuk pembelajaran yang menuntut kemampuan berpikir kritis siswa dalam memecahkan permasalahan kontekstual. PBL (Problem Based Learning) adalah model mengajar yang mengutamakan masalah sebagai fokus untuk mengembangkan keterampilan pemecahan masalah, berkomunikasi, materi dan pengaturan diri (Eggen \& Kauchak, 2012). PBL (Problem Based Learning) sebuah model pembelajaran yang berpusat pada siswa dari pendengaran informasi pasif menjadi aktif, mengembangkan masalah dan keteampilan pemecahan masalah (Ali et al., 2010). Pembelajaran dengan model PBL (Problem Based Learning) terjadi jika 
guru merancang dan melaksankan kegiatan pembelajaran yang dimulai dengan memberikan masalah kepada siswa. Proses pelaksanaan pembelajaran dengan PBL (Problem Based Learning) membutuhkan waktu yang lebih lama untuk menyelesaikan permasalahan yang diberikan guru sehingga waktu pelaksanaan harus disesuaikan dengan beban kurikulum yang ada. Solusi untuk melaksanakan PBL (Problem Based Learning) yaitu melaksanakan pembelajaran secara mandiri dengan bantuan bahan ajar yang sesuai.

Perkembangan ilmu pengetahuan saat ini semakin pesat sehingga mempermudah proses pembelajaran. Oleh karena itu, banyak fasilitas untuk membuat dan menciptakan bahan ajar yang menarik serta menunjang proses pembelajaran. Sesuai dengan perkembangan zaman, bahan ajar tidak hanya buku cetak tetapi tersedia internet maupun sumber lain seperti jurnal, artikel, buku elektronik (e-book), modul elektronik ( $e-m o d u l$ ), sehingga mempermudah siswa untuk mengakses materi yang dipelajari.

Berdasarkan studi pendahuluan, bahan ajar sudah tersedia di sekolah berupa buku cetak dari pemerintah, buku cetak dari penerbit lain, lembar kerja maupun modul. Namun, bahan ajar yang memanfaatkan teknologi belum ada, seperti e-modul. Selain itu, siswa mengalami banyak kesulitan dalam materi penyajian data. Oleh karena itu, perlu alternatif bahan ajar untuk digunakan dalam pembelajaran matematika, yaitu $e$ - modul matematika materi penyajian data dengan harapan $e$-modul menjadi bahan ajar inovatif yang dapat membuat siswa lebih termotivasi, tidak bosan saat pembelajaran.

E-modul adalah sebuah media pembelajaran berbentuk elektronik yang bisa dijalankan atau di buka melalui komputer dengan berbagai paduan software yang diperlukan, berisi berbagai materi yang di susun secara teratur dan menarik sesuai dengan kompetensi dan keinginan. E-modul adalah suatu tampilan informasi dalam format buku yang disajikan secara elektronik dan dibaca dengan menggunakan komputer atau alat elektronik lainnya (Wijayanto \& Zuhri, 2014). E-modul merupakan bagian dari electronic based learning yang memanfaatkan teknologi yaitu elektronik. Saat ini banyak alat bantu pembelajaran yang memanfaatkan media elektronik, diantaranya: teknologi ICT, teknologi multimedia, teknologi televisi, dan teknologi komputer. Penyusunan sebuah e-modul memerlukan program khusus, namun hasil yang di peroleh cukup inovatif karena dapat menampilkan bahan ajar yang lengkap, menarik, interaktif dan mengemban fungsi kognitif yang bagus (Najuah et al., 2020). Modul elektronik sangat baik digunakan dalam meningkatkan keikutsertaan siswa selama kegiatan belajar. Pembelajaran menggunakan modul elektronik (e-modul) merupakan belajar secara mandiri (Feriyanti, 2019). Komponen yang terdapat dalam e-modul yaitu cover, pendahuluan atau penjelasan umum $e$ modul, petunjuk penggunaan $e$-modul, kompetensi pembelajaran, peta konsep, lembar kegiatan, lembaran evaluasi, lembaran kuis, dan lain-lain.

Berdasarkan paparan di atas, perlu dikembangkan $e$-modul yang valid, praktis, dan efektif. $E$ modul diharapkan dapat mengajak siswa untuk meningkatkan cara berpikir siswa dalam menyelesaikan permasalahan secara kontekstual. Oleh karena itu, perlu dilakukan penelitian pengembangan dengan judul "Pengembangan E-modul Matematika Berbasis PBL (Problem Based Learning) Pada Materi 
Penyajian Data Untuk Siswa SMP”.

\section{METODE}

Penelitian ini menggunakan metode penelitian dan pengembangan (Research and Developme (R\&D)). Metode penelitian Research and Development (R\&D) berarti penelitian dan pengembangan untuk menghasilkan sebuah produk berupa bahan ajar, media pembelajaran, strategi pembelajaran evaluasi dan sebagainya. Subjek dalam penelitian pengembangan e-modul matematika berbasis $\mathrm{PBL}$ (Problem Based Learning) pada materi penyajian data untuk siswa SMP adalah siswa siswi kelas VII A SMP Negeri 11 Cilegon. Penelitian dan pengembangan ini menggunakan model pengembangan ADDIE. Model penelitian ADDIE terd apat lima tahap yang terdiri dari analisis (Analysis), perencanaan (Design), pengembangan (Development), implementasi (Implementation), dan evaluasi (evaluation) (Sugiyono, 2015). Model ADDIE memiliki komponen yang saling berkaitan dan terstruktur di mulai dari tahap awal sampai tahap akhir, tidak dapat di acak. Instrumen dalam penelitian ini, adalah: (1) Lembar validasi ditujukan kepada para ahli yaitu tiga ahli materi dan tiga ahli media, (2) Lembar angket respon ditujukan kepada guru matematika dan siswa kelas VII A SMP Negeri 11 Cilegon, dan (3) Soal tes ketuntasan ditujukan kepada siswa kelas VII A SMP Negeri 11 Cilegon setelah pembelajaran menggunakan e-modul yang dikembangkan.

Tabel 2. Kisi-kisi Validasi Ahli Materi

\begin{tabular}{|c|c|c|}
\hline NO & Indikator & Butir \\
\hline 1 & Aspek Pendahuluan & 1,2 \\
\hline 2 & Aspek Pembelajaran dan Isi & $3,4,5,6,7$ \\
\hline 3 & Aspek Kebahasaan & $8,9,10,11,12$ \\
\hline 4 & Aspek Evaluasi & $13,14,15$ \\
\hline
\end{tabular}

Tabel 3. Kisi-kisi Validasi Ahli Media

\begin{tabular}{|c|c|c|}
\hline NO & Indikator & Butir \\
\hline 1 & Aspek Tampilan Desain Layar & $1,2,3,4,5$ \\
\hline 2 & Aspek Kemudahan Penggunaan & $6,7,8,9$ \\
\hline 3 & Aspek Kesesuaian Bahasa & $10,11,12$ \\
\hline 4 & Aspek Kemanfaatan & $14,14,15$ \\
\hline 5 & Aspek Kegrafikan & $16,17,18,19,20$ \\
\hline
\end{tabular}

Tabel 4. Kisi-kisi Angket Respon Guru Matematika

\begin{tabular}{|c|c|c|}
\hline NO & Indikator & Butir \\
\hline 1 & Aspek Kualitas Isi & $1,2,3,4,5,6,7$ \\
\hline 2 & Aspek Kualitas Instruksional & 8,9 \\
\hline 3 & Aspek Kualitas Teknis & $11,12,13$ \\
\hline
\end{tabular}


Pengembangan E-Modul Matematika Berbasis PBL (Problem Based Learning) pada Materi Penyajian Data untuk Siswa SMP, Fatma Ramadanti, Anwar Mutaqin, Aan Hendrayana

Tabel 5. Kisi-kisi Angket Respon Siswa

\begin{tabular}{|c|c|c|}
\hline No & Indikator & Butir \\
\hline 1 & Aspek Desain & 1,2 \\
\hline 2 & Aspek Isi & $3,4,5,6,7$ \\
\hline 3 & Aspek Kebahasaan & $8,9,10$ \\
\hline
\end{tabular}

Tabel 6. Kisi-kisi Soal Tes Ketuntasan

\begin{tabular}{|c|c|c|c|c|}
\hline No & Kompetensi Dasar & Indikator Soal & Bentuk Soal & Nomor Soal \\
\hline 1 & $\begin{array}{l}\text { Menganalisis } \\
\text { hubungan antara } \\
\text { data dan cara } \\
\text { penyajian (table, } \\
\text { diagram garis, } \\
\text { diagram batang dan } \\
\text { diagram lingkaran) }\end{array}$ & $\begin{array}{l}\text { Disajikan data dalam diagram batang } \\
\text { berisikan hasil survey kegiatan } \\
\text { olahraga. Pada soal tersebut siswa } \\
\text { diminta untuk menentukan } \\
\text { banyaknya siswa yang memilih } \\
\text { olahraga bulu tangkis sebagai } \\
\text { olahraga favorit siswa dan } \\
\text { menentukan olahraga yang paling } \\
\text { diminati siswa. }\end{array}$ & Uraian & 1 \\
\hline 2 & $\begin{array}{l}\text { Menganalisis } \\
\text { hubungan antara } \\
\text { data dengan cara } \\
\text { penyajian (table, } \\
\text { diagram garis, } \\
\text { diagram batang dan } \\
\text { diagram lingkaran) }\end{array}$ & $\begin{array}{l}\text { Disajikan data pada tabel berisikan } \\
\text { banyak siswa di suatu kota } \\
\text { berdasarkan tingkat Pendidikan pada } \\
\text { soal tersebut. Siswa di minta untuk } \\
\text { menyajikan data tersebut ke dalam } \\
\text { bemtuk diagram lingkaran, siswa } \\
\text { diminta menentukan berapa persen } \\
\text { yang menyelesaikan pendidikan } \\
\text { sampai pada tingkat SMP dan SMA }\end{array}$ & Uraian & 2 \\
\hline 3 & $\begin{array}{l}\text { Menganalisis } \\
\text { hubungan antara } \\
\text { data dengan cara } \\
\text { penyajiannya } \\
\text { (table, diagram } \\
\text { garis, diagram } \\
\text { batang dan diagram } \\
\text { lingkaran) }\end{array}$ & $\begin{array}{l}\text { Disajikan data dalam bentuk table } \\
\text { data tersebut berisikan jenis } \\
\text { pekerjaan orang tua. Pada soal } \\
\text { tersebut siswa diminta untuk } \\
\text { menyajikan data tersebut ke dalam } \\
\text { bentuk diagram garis, diagram } \\
\text { lingkaran serta membuat kesimpulan } \\
\text { terhadap kedua diagram yang dibuat. }\end{array}$ & Uraian & 3 \\
\hline 4 & $\begin{array}{l}\text { Menyajikan dan } \\
\text { menyelesaikan } \\
\text { masalah yang } \\
\text { berkaitan dengan } \\
\text { distribusi data, nilai } \\
\text { rata-rata (mean), } \\
\text { median, modus dan } \\
\text { sebaran. }\end{array}$ & $\begin{array}{l}\text { Disajikan diagram batang terkait } \\
\text { berat badan siswa SMP Bintang } \\
\text { Pelita, kemudian siswa diminyta } \\
\text { untuk menentukan rata-rata, median, } \\
\text { dan modus berdasaarkan data di atas. }\end{array}$ & Uraian & 4 \\
\hline 5 & $\begin{array}{l}\text { Menyajikan dan } \\
\text { menyelesaikan } \\
\text { masalah yang } \\
\text { berkaitan dengan } \\
\text { distribusi data, nilai } \\
\text { rata-rata (mean), } \\
\text { median, modus dan } \\
\text { sebaran. }\end{array}$ & $\begin{array}{l}\text { Disajikan tabel data nilai ujian } \\
\text { matematika siswa kellas VIII. Siswa } \\
\text { diminta menentukan pernyataan } \\
\text { dengan tabel benar atau tidak } \\
\text { kemudian jelaskan dan menentukan } \\
\text { modus dan median. }\end{array}$ & Uraian & 5 \\
\hline
\end{tabular}


Teknik analisis data yang digunakan pada penelitian ini adalah analisis kuantitatif dan kualitatif. Data yang diperoleh dari validator, angket guru, angket siswa dan soal tes ketuntasan menggunakan analisis kuantitatif. Sedangkan kritik, saran, dan masukan dari validator dan guru menggunakan analisis kualitatif.

\section{HASIL DAN DISKUSI}

Sebelum penelitian dilakukan, peneliti menyerahkan surat permohonan izin penelitian kepada kepala sekolah SMP Negeri 11 Cilegon untuk mendapatkan persetujuan melaksanakan penelitian pada siswa kelas VII A Tahun ajaran 2021/2022. Setelah mendapatkan persetujuan dari pihak sekolah, peneliti melakukan wawancara tidak terstruktur pada guru mata pelajaran matematika kelas VII A membahas sumber belajar yang digunakan oleh guru dan siswa, kegiatan pembelajaran selama pandemi, dan kesulitan belajar matematika khususnya pada materi statistika atau penyajian data. Hal tersebut bertujuan agar e-modul yang dirancang dapat memfasilitasi siswa dalam pembelajaran matematika siswa SMP.

Tahap selanjutnya, peneliti merancang $e$-modul. Dalam merancang e-modul hal pertama yang dilakukan adalah menaganalisis yang terdiri dari analisis kurikulum, analisis kebutuhan, dan analisis siswa. Kemudian, tahap desain yaitu penyusunan kerangka e-modul, penyusunan materi, dan peranangan instrument. Selanjutnya, meminta tenaga ahli yang sudah berpengalaman pada bidanya untuk menilai produk yang dikembangkan (Khaerunnisa et al., 2019) meminta ahli ntuk memvalidasi produk yang dikembangkan, kemudian revisi e-modul. Beberapa bagian e-modul disajikan dalam gambar berikut.

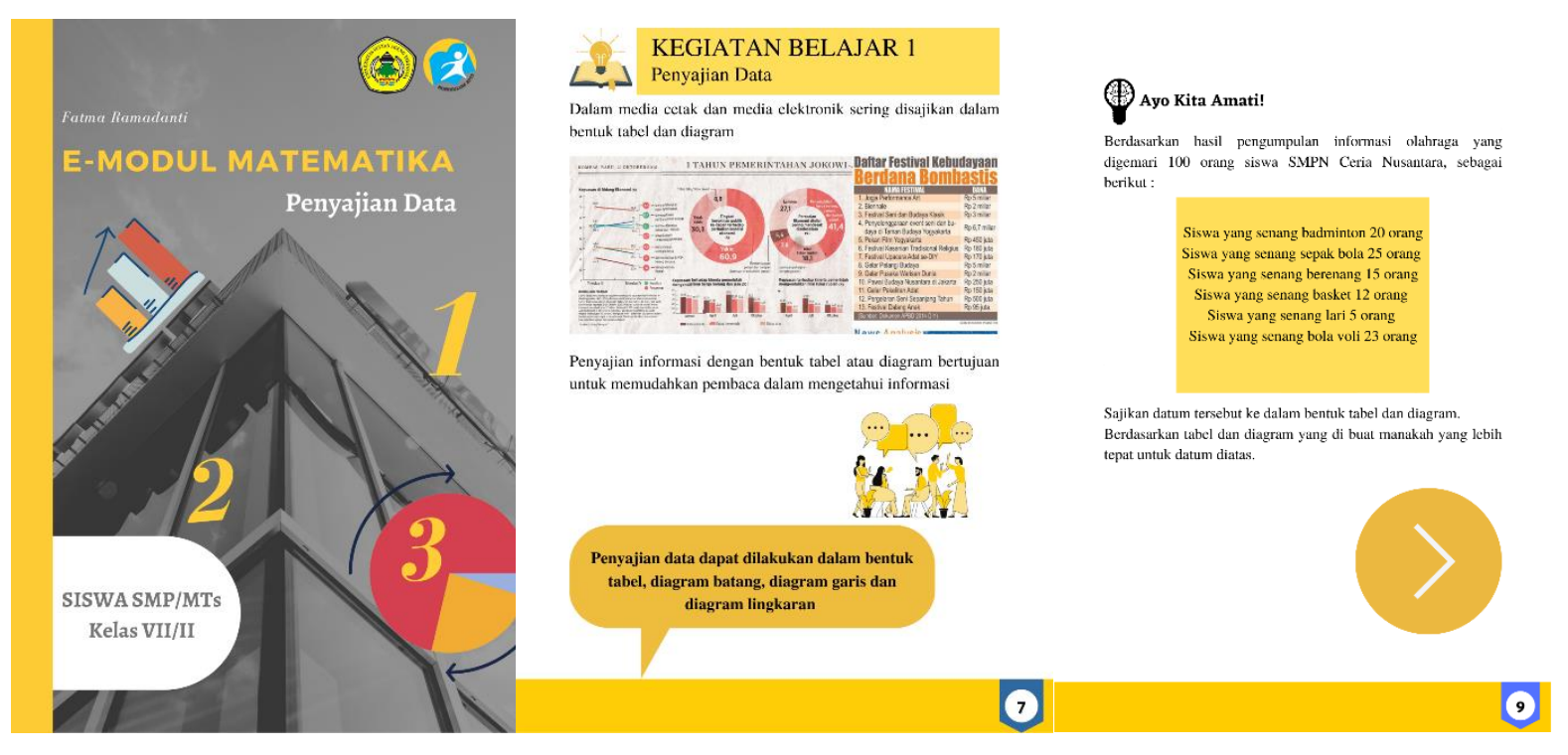

Gambar 1. Bagian E-Modul 


$$
\text { !. Masalah } 1
$$

Budidaya Udang merupakan saliah satu sektor penyumbang terbanyak hasil udang di kepulatan Riau. Berdasarkan has budidaya udang di kepulauan Riau tersebut di ambil beberap data bulan januari 2019 di beberapa pulau secara acak dalar satuan ton.

(14

$\begin{array}{lllllllllll}14 & 18 & 18 & 11 & 14 & 20 & 15 & 13 & 14 & 13\end{array}$ 16 17 12 13 16 160100

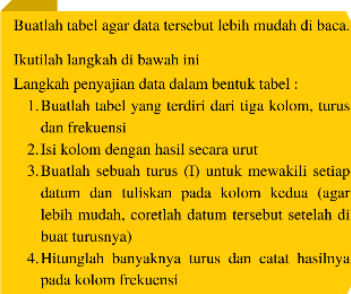

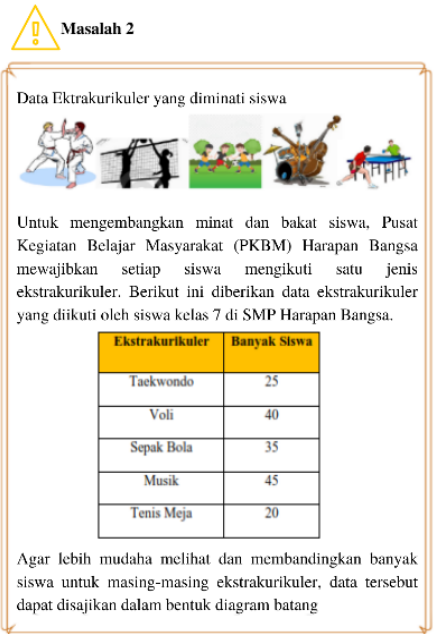

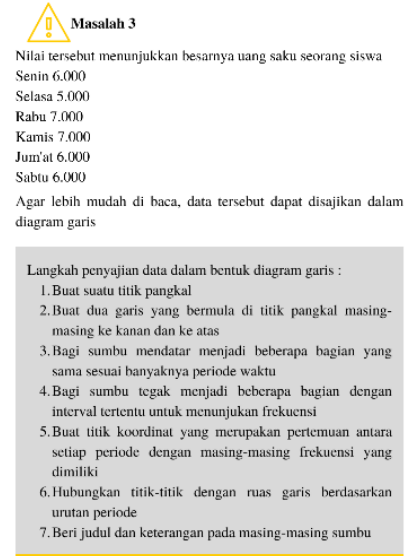

10

Gambar 2. Bagian E-Modul

Tahap penting setelah produk yang dikembangkan selesai adalah tahap implementasi yaitu dilakukan uji coba. Peneliti melakukan uji coba $e$-modul pada peserta didik kelas VII A SMP Negeri 11 Cilegon tahun pelajaran 2021/2022. Pelaksanaan uji coba dilakukan oleh guru matematika yang dilakukan secara daring. Guru memberikan informasi kepada siswa untuk mengerjakan uji kompetensi yang terdapat pada e-modul dan mengumpulkan hasilnya pada link yang telah dikirimkan pada grup whatsapp. Jawaban siswa, sebagai berikut:

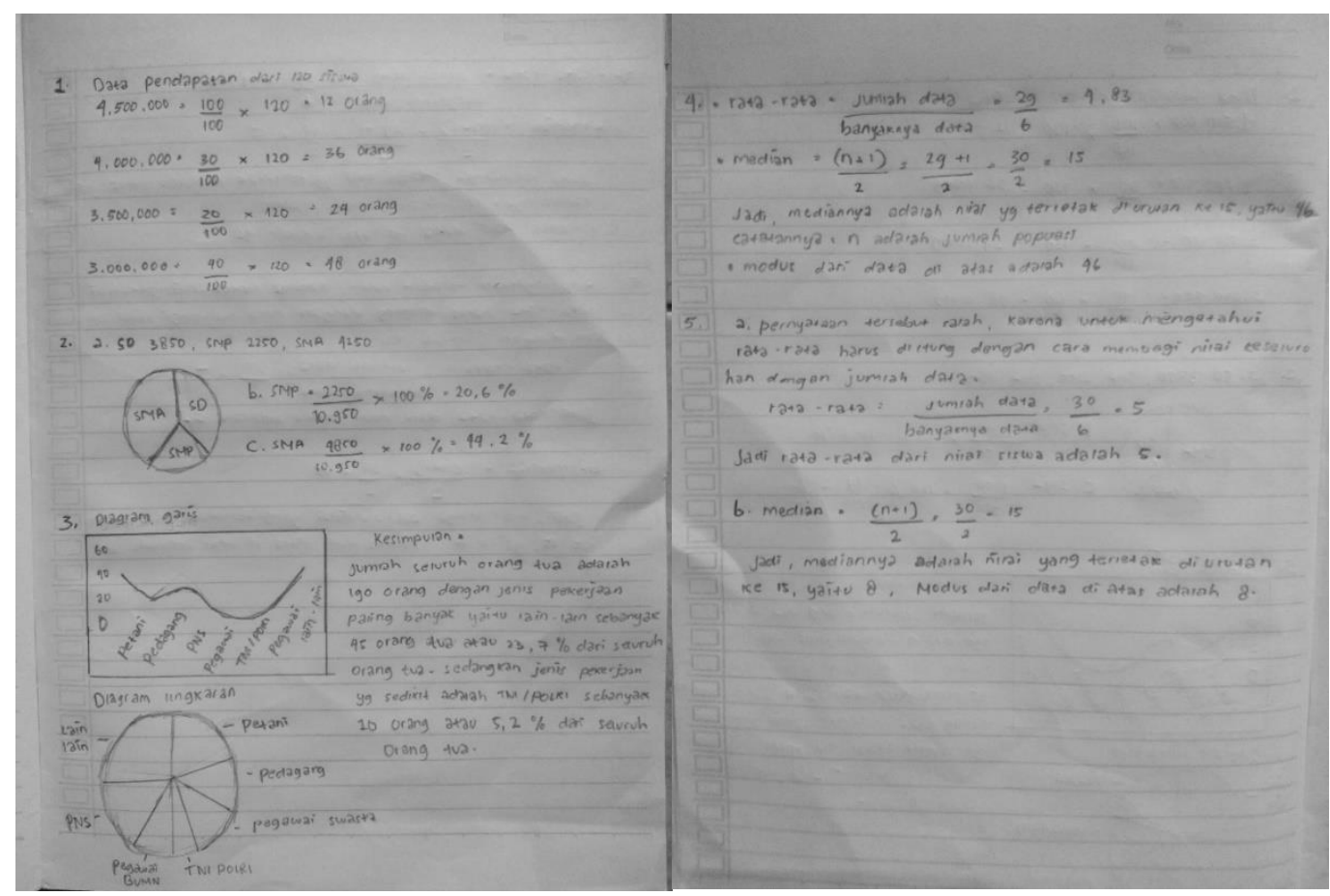

Gambar 3. Jawaban Siswa 
Penelitian ini menghasilkan produk berupa e-modul atau modul elektronik yang valid, praktis, dan efektif untuk kelas VII SMP pada materi penyajian data. Pada penelitian ini untuk mengetahui kevalidan atau kelayakan e-modul dilakukan proses validasi produk yang melibatkan enam orang validator yaitu tiga ahli materi dan tiga ahli media. Validasi ahli materi bertujuan menilai materi yang ada pada e-modul, sedangkan validasi ahli media bertujuan menilai produk berupa modul elektronik dari segi medianya.

Tabel 7. Rekapitulasi Data Hasil Validasi Ahli Materi

\begin{tabular}{|c|c|c|}
\hline No & Indikator & Rata-rata tiap aspek \\
\hline 1 & Aspek Pendahuluan & 4,335 \\
\hline 2 & Aspek Pembelajaran dan Isi & 4,2 \\
\hline 3 & Aspek Kebahasaan & 4,33 \\
\hline 4 & Aspek Evaluasi & 4,446 \\
\hline & Rata-rata Total Validitas (RTV) & 4,32 \\
\hline
\end{tabular}

Tabel 8. Rekapitulasi Data Hasil Validasi Ahli Media

\begin{tabular}{|c|c|c|}
\hline No & Indikator & Rata-rata tiap aspek \\
\hline 1 & Aspek Tampilan Desain Layar & 4,532 \\
\hline 2 & Aspek Kemudahan Penggunaan & 4,75 \\
\hline 3 & Aspek Kesesuaian Bahasa & 4,11 \\
\hline 4 & Aspek Kemanfaatan & 4,77 \\
\hline 5 & Aspek Kegrafikan & 4,198 \\
\hline \multicolumn{2}{|c|}{ Rata-rata Total Validitas (RTV) } & 4,472 \\
\hline
\end{tabular}

Berdasarkan rekapitulasi data hasil validasi ahli materi diperoleh rata-rata total validasi (RTV) sebesar 4,32 dengan kriteria "sangat baik" saran dari validator materi harus di revisi yaitu memperbaiki redaksi dan kesalahan pengetikan pada e-modul dan rekapitulasi data hasil validasi ahli media diperoleh rata-rata total validasi (RTV) sebesar 4,472 dengan kriteria "sangat baik". Berdasarkan hasil validasi ahli materi dan ahli media yang sudah dilakuakn kemudian dilakukan analisis dengan hasil yang sudah dijabarkan di atas, maka dapat disimpulan bahwa e-modul matematika berbasis Problem Based Learning (PBL) Pada Materi Penyajian Data untuk siswa SMP termasuk dalam kategori "Sangat Valid" atau layak untuk diimplementasikan. Pada penelitian ini untuk mengetahui kepraktisan e-modul peneliti memberikan angket kepada guru matematika dan siswa kelas VII A dengan tujuan mengetahui pendapat guru dan siswa terkait kepraktisan e-modul yang dikembangkan.

Tabel 9. Hasil Angket Respon Guru Matematika

\begin{tabular}{|c|c|c|c|}
\hline No & Aspek & Persentase & Kriteria \\
\hline 1 & Aspek Kualitas Isi & $82 \%$ & Sangat Baik \\
\hline 2 & Aspek Kualitas Instruksional & $80 \%$ & Baik \\
\hline 3 & Aspek Kualitas Teknis & $80 \%$ & Baik \\
\hline
\end{tabular}


Pengembangan E-Modul Matematika Berbasis PBL (Problem Based Learning) pada Materi Penyajian Data untuk Siswa SMP, Fatma Ramadanti, Anwar Mutaqin, Aan Hendrayana

Tabel 10. Hasil Angket Respon Siswa

\begin{tabular}{|c|c|c|c|c|c|}
\hline No & Indikator & Aspek penilaian & $\begin{array}{c}\text { Total Nilai } \\
\text { Kepraktisan }\end{array}$ & $\% \mathrm{NK}$ & Kategori \\
\hline & \multirow{2}{*}{$\begin{array}{l}\text { Aspek } \\
\text { Desain }\end{array}$} & Desain $e$-modul menarik & 88 & $88 \%$ & Sangat Baik \\
\hline 2 & & Kejelasan judul $e$-modul & 86 & $86 \%$ & Sangat Baik \\
\hline 3 & \multirow{5}{*}{ Aspek Isi } & $\begin{array}{l}\text { E-modul menarik untuk } \\
\text { digunakan dalam } \\
\text { pembelajaran }\end{array}$ & 90 & $90 \%$ & Sangat Baik \\
\hline 4 & & $\begin{array}{l}\text { Contoh soal berkaitan dengan } \\
\text { kehidupan sehari-hari }\end{array}$ & 81 & $81 \%$ & Sangat Baik \\
\hline 5 & & $\begin{array}{l}\text { Materi dalam e-modul mudah } \\
\text { dipahami }\end{array}$ & 88 & $88 \%$ & Sangat Baik \\
\hline 6 & & $\begin{array}{l}\text { Ilustrasi gambar dan video } \\
\text { membantu dalam memahami } \\
\text { materi }\end{array}$ & 87 & $87 \%$ & Sangat Baik \\
\hline 7 & & $\begin{array}{l}\text { E-modul disajikan dengan } \\
\text { runtut dan jelas }\end{array}$ & 86 & $86 \%$ & Sangat Baik \\
\hline 8 & \multirow{3}{*}{$\begin{array}{c}\text { Kebahasaa } \\
n\end{array}$} & $\begin{array}{l}\text { Istilah yang di gunakan pada } \\
e \text {-modul lazim untuk siswa }\end{array}$ & 87 & $87 \%$ & Sangat Baik \\
\hline 9 & & $\begin{array}{l}\text { Kalimat dan paragraf yang } \\
\text { digunakan jelas dan mudah } \\
\text { dipahami }\end{array}$ & 91 & $91 \%$ & Sangat Baik \\
\hline 10 & & $\begin{array}{l}\text { Kalimat yang digunakan } \\
\text { mewakili isi, pesan dan } \\
\text { informasi yang ingin } \\
\text { disampaikan sesuai dengan } \\
\text { Pedoman Umum Ejaan } \\
\text { Bahasa Indonesia (PUEBI) }\end{array}$ & 88 & $88 \%$ & Sangat Baik \\
\hline & & Rata-rata & 87,2 & $87,2 \%$ & Sangat baik \\
\hline
\end{tabular}

Berdasarkan tabel 9 hasil angket respon guru pada aspek kualitas isi memperoleh persentase sebesar $82 \%$, pada aspek kualitas instruksional memperoleh persentase sebesar $80 \%$ dan pada aspek kualitas teknis memperoleh persentase sebesar $80 \%$. Oleh karena itu, kriteria kepraktisan e-modul yang dikembangkan dari respon guru adalah sangat baik. Kemudian, kepraktisan e-modul yang dikembangkan lainnya adalah angket respon siswa. Angket respon siswa dari 20 siswa SMP Negeri 11 Cilegon kelas VII A mandapatkan nilai rata-rata perentase nilai kepraktisan sebesar 87,2\%, maka dapat disimpulkan bahwa e-modul matematika berbasis Problem Based Learning (PBL) Pada Materi Penyajian Data untuk siswa SMP adalah praktis. Keefektifan $e$-modul dikembangkan berdasarkan hasil tes ketuntasan yang diberikan kepada siswa kelas VII A.

Tabel 11. Hasil Tes Ketuntasan Individual

\begin{tabular}{|c|c|c|c|}
\hline No & Nama & Skor & Keterangan \\
\hline 1 & M1 & 30 & Belum Tuntas \\
\hline 2 & M2 & 100 & Tuntas \\
\hline
\end{tabular}




\begin{tabular}{|c|c|c|c|}
3 & M3 & 100 & Tuntas \\
\hline 4 & M4 & 85 & Tuntas \\
\hline 5 & M5 & 100 & Tuntas \\
\hline 6 & M6 & 32 & Belum Tuntas \\
\hline 7 & M7 & 100 & Tuntas \\
\hline 8 & M8 & 100 & Tuntas \\
\hline 9 & M9 & 100 & Tuntas \\
\hline 10 & M10 & 100 & Tuntas \\
\hline 11 & M11 & 100 & Tuntas \\
\hline 12 & M12 & 100 & Tuntas \\
\hline 13 & M13 & 100 & Tuntas \\
\hline 14 & M14 & 40 & Belum Tuntas \\
\hline 15 & M15 & 55 & Belum Tuntas \\
\hline 16 & M16 & 95 & Tuntas \\
\hline 17 & M17 & 90 & Tuntas \\
\hline 18 & M18 & 75 & Tuntas \\
\hline 19 & M19 & 100 & Tuntas \\
\hline 20 & M20 & 90 & Tuntas \\
\hline
\end{tabular}

Tabel 12. Hasil Tes Ketuntasa Klasikal

\begin{tabular}{|c|c|c|}
\hline Keterangan siswa & Jumlah Siswa & Persentase \\
\hline Siswa yang Tuntas & 16 & $85 \%$ \\
\hline Siswa yang Belum Tuntas & 4 & $15 \%$ \\
\hline
\end{tabular}

Berdasarkan tabel 11 diketahui bahwa Kriteria Ketuntasan Minimal (KKM) yang telah ditetapkan SMP Negeri 11 Cilegon, siswa mampu mencapai nilai ketuntasan secara individual meskipun terdapat siswa yang belum mencapai Kriteria Ketuntasan Minimal (KKM). Siswa yang sudah mencapai KKM secara individual sebanyak 16 siswa, sedangkan 4 siswa lainnya masih dibawah Kriteria Ketuntasan Minimal (KKM). Berdasarkan tabel 12 diketahui bahwa jumlah persentase siswa yang tuntas sebesar $85 \%$, sedangkan jumlah persentase siswa yang belum tuntas sebesar 15\%. Jadi, dapat disimpulkan bahwa siswa telah mencapai kompetensi yang telah ditentukan. Berdasarkan hasil ketuntasan siswa secara individual maupun klasikal dapat disimpulkan bahwa $e$-modul matematika berbasis PBL (Problem Based Learning) pada materi penyajian data memenuhi kategori "efektif".

Produk yang telah selesai dikembangkan berupa e-modul atau modul elektronik. Berdasarkan hasil studi pendahuluan, diketahui bahwa guru belum menggunakan bahan ajar seperti elektronik modul, bahan ajar yang digunakan sebagai pedoman pembelajaran hanya menggunakan buku cetak. Pada kurikulum 2013, seharusnya sekolah-sekolah sudah menggunakan bahan ajar berupa BAE (Bahan Ajar Elektronik), buku yang disediakan gratis oleh penerbit atau hak ciptanya sudah dibeli atau disajikan dalam bentuk e-modul atau e-book atau PDF. E-modul ini ditujukan untuk sekolah menengah pertama 
(SMP) kelas VII dan dirancang untuk memenuhi kebutuhan siswa agar belajar dengan nyaman dan mandiri (Nurdyansyah \& Mutala'liah, 2015).

Hasil penelitian menunjukkan bahwa e-modul matematika berbasis Problem Based Learning (PBL) pada materi penyajian data untuk siswa SMP memenuhi kriteria valid, praktis, dan efektif, sehingga layak untuk digunakan dalam pembelajaran matematika. Penelitian ini sejalan dengan penelitian-penelitian yang telah dilakukan oleh (Rahayu et al., 2016) dan (Rochsun \& Agustin, 2020). E-modul matematika yang dihasilkan dalam penelitian ini diharapkan dapat meningkatkan keaktifan siswa dalam pembelajarn matematika dan menambah bahan ajar bagi guru matematika.

Penelitian juga menunjukkan bahwa e-modul matematika berbasis Problem Based Learning (PBL) efektif untuk digunakan ditinjau dari prestasi belajar siswa pada materi penyajian data. Hal tersebut tidak terlepas dari adanya aktivitas yang mampu meningkatkan peran aktif siswa melalui langkah-langkah Problem Based Learning (PBL), sesuai dengan teori belajar yaitu mengaitkan informasi baru dengan struktur kognitif yang dimiliki siswa. Efektifnya e-modul yang dikembangkan tidak terlepas juga dari penyajian masalah yang menjadi titik awal pembelajaran sampai mengevaluasi hasil pemecahan masalah. Pada awal pembelajaran pendidik memberikan suatu permasalahan dengan tujuan memberikan pancingan kepada siswa untuk mengaitkan informasi yang sudah dimiliki dengan informasi yang pendidik sampaikan, hal ini selaras dengan teori belajar ausubel agar pembelajaran menjadi lebih bermakna.

\section{KESIMPULAN}

Penelitian pengembangan ini bertujuan untuk mendeskripsikan proses dan kualitas dari produk yang dikembangkan yaitu e-modul. Berdasarkan hasil penelitian dan pembahasan yang telah dilakukan, maka diperoleh kesimpulan, sebagai berikut: (1) E-modul matematika berbasis Problem Based Learning (PBL) pada materi penyajian data untuk siswa SMP berhasil dikembangkan dalam penelitian ini. Pada validasi ahli materi mendapat nilai rata-rata total validitas (RTV) sebesar 4,32 dan pada validasi ahli media mendapatkan nilai rata- rata total validitas (RTV) sebesar4,472, sehingga termasuk dalam kategori "Sangat Valid" atau layak untuk diimplementasikan/digunakan. (2) E-modul matematika berbasis Problem Based Learning (PBL) pada materi penyajian data untuk siswa SMP dinyatakan "praktis" dengan nilai rata-rata persentase respon angket guru pada aspek kualitas isi memperoleh persentase sebesar $82 \%$, pada aspek kualitas instruksional memperoleh persentase sebesar $80 \%$ dan pada aspek kualitas teknis memperoleh persentase sebesar $80 \%$ sedangkan nilai rata-rata persentase respon angket siswa sebesar 87,2\%. (3) Hasil Tes Ketuntasan siswa kelas VII A SMP Negeri 11 Cilegon dalam pembelajaran matematika materi penyajian data menggunakan e-modul yang dikembangkan mendapatkan persentase siswa yang tuntas sebesar $85 \%$, sedangkan jumlah persentase siswa yang belum tuntas sebesar 15\%, maka dapat disimpulkan bahwa siswa telah mencapai kompetensi yang telah ditentukan dan secara individual maupun klasikal e-modul matematika berbasis PBL (Problem Based Learning) pada materi penyajian data memenuhi kategori "efektif". 


\section{UCAPAN TERIMA KASIH}

Saya mengucapkan terima kasih kepada Ibu Kepala Sekolah, Guru Matematika dan seluruh siswa kelas VII A SMP Negeri 11 Cilegon atas dukungan, isin, dan pertisipasinya dalam pelaksanaan penelitian ini.

\section{REFERENSI}

Ali, R., Hukamdad, D., Akhter, A., \& Khan, A. (2010). Effect of Using Problem Solving Method in Teaching Mathematics on the Achievement of Mathematics Students. Asian Social Science, 6(2), 67-72. https://doi.org/10.5539/ass.v6n2p67

Eggen, P., \& Kauchak. (2012). Strategi dan Model Pembelajaran. Indeks.

Feriyanti, N. (2019). Pengembangan E-Modul Matematika Untuk Siswa SD ( The Development of EModul Mathematics For Primary Students ). Teknologi Pendidikan Dan Pembelajaran, 1-12.

Khaerunnisa, E., Rafianti, I., Pamungkas, A. S., Pujiastuti, H., \& Setiani, Y. (2019). Development of a Content Management System (CMS) for Mathematics Learning Tools Of Mathematics Pre Service Teachers. Formatif: Jurnal Ilmiah Pendidikan MIPA, 9(2), 117-130. https://doi.org/10.30998/formatif.v9i2.2978

Maryati, I., \& Nanang. (2017). Analisis Kesulitan Dalam Materi Statistika Ditinjau Dari Kemampuan Penalaran Dan Komunikasi Statistis. Prisma, 6(2), 173-179. https://doi.org/10.35194/jp.v6i2.209

Najuah, N., Lukitoyo, Suhendro, P., \& Wirianti, W. (2020). Modul Elektronik: Prosedur Penyusunan dan Aplikasinya (Janner Simarmata (ed.)). Yayasan Kita Menulis.

Nurdyansyah, \& Mutala'liah, N. (2015). Pengembangan Bahan Ajar Modul Ilmu Pengetahuan Alambagi Siswa Kelas IV Sekolah Dasar. Program Studi Pendidikan Guru Madrasa Ibtida 'iyah Fakultas Agama Islam Universitas Muhammadiyah Sidoarjo, 41(20), 1-15.

Rahayu, R., Parta, I., \& Rahardjo, S. (2016). Pengembangan Perangkat Pembelajaran Bercirikan Konstruktivis Tipe Gagnon Dan Collay Pada Materi Penyajian Data Untuk Siswa Kelas Vii. Jurnal Pendidikan: Teori, Penelitian, Dan Pengembangan, 1(7), 1279-1286. https://doi.org/10.17977/jp.v1i7.6529

Rochsun, \& Agustin, ririn dwi. (2020). THE DEVELOPMENT OF E-MODULE MATHEMATICS. 400412. https://doi.org/10.46827/ejes.v7i10.3317

Sirait, E. D. (2016). Pengaruh Minat Belajar Terhadap Prestasi Belajar Matematika. Formatif: Jurnal Ilmiah Pendidikan MIPA, 6(1), 35-43. https://doi.org/10.30998/formatif.v6i1.750

Sugiyono. (2015). Metode Penelitian Kuantitatif Kualitatif dan $R \& D$. Alfabeta CV.

Sukadiono, radius setyawan, dede nasrullah. (2020). Alam Pikir Era Pandemi: Kajian Lintas Ilmu.

Wijayanto, \& Zuhri, M. S. (2014). Pengembangan E-Modul Berbasis Flip Book Maker Dengan Model Project Based Learning Untuk Mengembangkan Kemampuan Pemecahan Masalah Matematika. Prosiding Mathematics and Sciences Forum 2014, 625-628. http://prosiding.upgris.ac.id/index.php/masif2014/masif2014/paper/viewFile/487/436 
Pengembangan E-Modul Matematika Berbasis PBL (Problem Based Learning) pada Materi Penyajian Data untuk Siswa SMP, Fatma Ramadanti, Anwar Mutaqin, Aan Hendrayana

Zhafira, N. H., Ertika, Y., \& Chairiyaton. (2020). Persepsi Mahasiswa Terhadap Perkuliahan Daring Sebagai Sarana Pembelajaran Selama Masa Karantina Covid-19. Jurnal Bisnis Dan Kajian Strategi Manajemen, 4, 37-45.

Zulfikri. (2016). Pengaruh Mata Kuliah Statistik Terhadap Kemampuan Analisa Data Kuantitatif Mahasiswa Prodi S-1 Ilmu Perpustakaan Angkatan 2011-2012 Fakultas Adab dan Humaniora UIN Ar-Raniry. Libria, 8(1), 112. https://jurnal.ar-raniry.ac.id/index.php/libria/article/view/1229. 